\title{
Second-Order Multipole Formulas for Thermal Resistance of Single U-tube Borehole Heat Exchangers
}

Saqib Javed

\begin{abstract}
The borehole thermal resistance is both an important design parameter and a key performance characteristic of a borehole heat exchanger. Another quantity that is particularly important for deep borehole beat exchangers is the internal thermal resistance between the upward-flowing and downward-flowing fluid channels in the borehole. The multipole method is a well-known and robust method to compute both these thermal resistances. However, it has a fairly intricate mathematical algorithm and is thus not trivial to implement. Consequently, there is considerable interest in developing explicit multipole formulas. So far zeroth-order and first-order multipole formulas have been derived for cases where the two legs of the borehole are placed symmetrically in a borehole. This paper presents new explicit second-order multipole formulas, which provide significant accuracy improvements over the previous formulas.
\end{abstract}

\section{INTRODUCTION, SCOPE AND RATIONALE}

Compared to ambient air, ground, in general, is a far superior source or sink of thermal energy because of its relatively stable temperature levels over the year. Since the turn of this century, the use of heating and cooling systems utilizing the ground as a heat source or a heat sink has grown at a remarkable rate (Lund and Boyd, 2016), stimulated by energy prices, technology advances and environmental concerns. A typical ground source heating or cooling system consists of a heat pump, a ground heat exchanger, and auxiliary systems for storage and distribution of thermal energy. The ground heat exchanger can be of open or closed type. In an open system groundwater is directly used as the heat carrier fluid, whereas in a closed system the heat carrier fluid is circulated in a closed loop, which can be horizontal or vertical. Various heat exchanger configurations can be used in closed-loop vertical systems, including single or double U-tubes, and simple or complex coaxial pipes. Among all types, a borehole heat exchanger with a single U-tube is by far the most commonly used ground heat exchanger in practice because of its low cost, small space requirements, and ease of installation. The scope of this paper is also limited to the application of single U-tubes in borehole heat exchangers.

Ground thermal conductivity $(\lambda)$ and borehole thermal resistance $\left(R_{b}\right)$ are the two principal parameters that govern the heat transfer mechanism of a borehole heat exchanger. The heat transfer outside the borehole boundary is dictated by the thermal conductivity of the ground, whereas the heat transfer inside the borehole is characterized by the borehole thermal resistance between the heat carrier fluid and the borehole wall. A high ground thermal conductivity is beneficial for the ground heat transfer. However, being an intrinsic property of ground, the ground thermal conductivity cannot be controlled in practice. On the other hand, a low borehole thermal resistance is desirable for better heat transfer inside the borehole. The borehole thermal resistance depends upon the physical arrangement and the thermal properties of borehole components including grouting, ground heat exchanger, and the heat carrier fluid. Its value can be engineered to a certain extent by optimizing the geometry and layout of the ground heat exchanger and by choosing appropriate materials for the borehole components.

Saqib Javed (saqib.javed@chalmers.se) is a researcher at Chalmers University of Technology and a Senior Lecturer at Lund University, Sweden. Johan Claesson is a Professor at Chalmers University of Technology and Lund University, Sweden. 
In physical terms, the thermal resistance of a borehole can be thought of as a ratio of the temperature difference between the heat carrier fluid and the borehole wall to the heat transfer rate per unit length of the borehole. This implies that reducing the borehole thermal resistance for a given heat transfer rate corresponds to minimizing the temperature difference between the heat carrier fluid and the borehole wall. There are basically two fundamental and well-established approaches for determining the thermal resistance of borehole heat exchangers: theoretical and experimental. In the theoretical approaches (Javed and Spitler, 2016), analytical or empirical formulas based on one- or two-dimensional steady-state conductive heat transfer are used to calculate the borehole thermal resistance. The borehole thermal resistance calculated by the theoretical approach is defined locally at a specific depth in the borehole. For a single Utube heat exchanger, the heat carrier fluid temperature is the local average temperature of the fluid in the two legs of the U-tube at a specific depth in the borehole. The same is represented as Equation 1, where $T_{\mathrm{f}, 1}$ is the local mean fluid temperature, $T_{\mathrm{b}}$ is the mean borehole wall temperature and $q_{\mathrm{b}}$ is the heat transfer rate per unit length of the borehole.

$$
R_{\mathrm{b}}=\frac{T_{\mathrm{f}, 1}-T_{\mathrm{b}}}{q_{\mathrm{b}}}
$$

The thermal resistance of the borehole heat exchanger, together with the ground thermal conductivity, can be determined experimentally (Javed et al., 2012) through an in-situ thermal response test. Most thermal response test evaluation methods use the mean of the temperatures taken at the inlet and outlet of a borehole. The temperature measurements taken at the top of the borehole account for the effects of thermal short-circuiting between the upward and downward flow channels of the ground heat exchanger. The thermal short-circuiting between the counter flow channels negatively impacts the heat carrier fluid temperature, which consequently results in a higher borehole thermal resistance than calculated with Equation 1 . This leads to the concept of effective borehole thermal resistance $R_{\mathrm{b}}^{*}$, which can be defined as the effective resistance between the heat carrier fluid $T_{\mathrm{f}}$, characterized by the simple mean of the inlet and outlet temperatures, and the mean borehole wall temperature $T_{\mathrm{b}}$. The effective borehole thermal resistance is mathematically expressed as Equation 2.

$$
R_{\mathrm{b}}^{*}=\frac{T_{\mathrm{f}}-T_{\mathrm{b}}}{q_{\mathrm{b}}}
$$

Unfortunately, the concepts of borehole thermal resistance and effective borehole thermal resistance have often been misunderstood both in research and practice (Javed and Spitler, 2016). This has led to indiscriminate and interchangeable use of these terms in research literature, causing confusion and discrepancies in calculating and analysing the borehole thermal resistance. The fundamental difference between the borehole thermal resistance defined by Equation 1 and the effective borehole thermal resistance defined by Equation 2 is that the former is defined locally at a specific borehole depth whereas the latter applies to the entire borehole. Depending on the depth of the borehole and the thermal capacitance of the heat carrier fluid, the effective borehole thermal resistance is higher than the local borehole thermal resistance by a few to several hundred percent (Javed and Spitler, 2016; Spitler et al., 2016a). For the most common borehole heat exchanger configurations, the effective borehole thermal resistance can be determined from the local borehole thermal resistance using the analytical expressions of Hellström (1991), Zeng et al. (2003) or Ma et al. (2015).

Hellström (1991) has derived Equations 3 and 4 for calculating the effective borehole thermal resistance of a single Utube borehole heat exchanger. The two equations are respectively based on uniform borehole wall temperature and uniform heat flux boundary conditions along the borehole. These are both limiting boundary conditions and the real situation falls somewhere in between. Hence, the effective borehole thermal resistance is sometimes expressed as the mean value between the two equations. Calculation of effective borehole thermal resistance with Equations 3 and 4 requires knowledge of total internal thermal resistance $R_{a}$ and direct coupling resistance $R_{1-2}$ between the two $U$-tube legs, respectively, in addition to the borehole thermal resistance $R_{b}$. All these resistances can be calculated to a high degree of accuracy by means of the well-known Multipole method (Claesson and Hellström, 2011). 


$$
\begin{gathered}
R_{\mathrm{b}}^{*}=R_{\mathrm{b}}+\frac{1}{3 R_{\mathrm{a}}}\left(\frac{H}{\rho_{\mathrm{f}} C_{\mathrm{f}} V_{\mathrm{f}}}\right)^{2} \\
R_{\mathrm{b}}^{*}=R_{\mathrm{b}} \eta \operatorname{coth} \eta, \quad \eta=\frac{H}{\rho_{\mathrm{f}} C_{\mathrm{f}} V_{\mathrm{f}}} \frac{1}{2 R_{\mathrm{b}}} \sqrt{1+\frac{4 R_{\mathrm{b}}}{R_{1-2}}}
\end{gathered}
$$

The multipole method is an analytical method based on two-dimensional steady-state conductive heat transfer in a borehole. It uses a combination of line heat sources and so-called multipoles to determine thermal resistances for any number of arbitrarily placed pipes in a composite region. The accuracy of the results increases with the number of multipoles used for the calculation. When implemented in a computer program, the order of the multipoles to be used for a calculation is typically prescribed to 10, which was the maximum possible order in the original (Bennet et al., 1987) implementation of the multipole method. Popular ground heat exchanger programs EED (Blocon, 2015) and GLHEPRO (Spitler, 2000) also use tenth-order multipoles when calculating the borehole thermal resistance. The tenthorder multipole calculations have an accuracy of over eight decimal digits (Claesson, 2012). However, on the adverse side, the multipole method has a quite rigorous mathematical formulation and a fairly complex algorithm. Its implementation in computer programs requires a considerable amount of coding - the original implementation in FORTRAN by Bennet et al. (1987) was nearly 600 lines in length. As a result, there has been considerable interest in simplifying the multipole method for typical borehole configurations. So far, closed-form multipole formulas for zerothorder and first-order have been developed for the case of a single U-tube with symmetrical pipes.

This paper presents newly derived closed-form multipole formulas of second-order. The presented formulas include expressions for borehole thermal resistance $R_{b}$, total internal thermal resistance $R_{a}$ and direct coupling resistance $R_{1-2}$. The formulas also allow the calculation of effective borehole thermal resistance from Equations 3 and 4 . The accuracy of the presented formulas is established by comparing them to the original multipole method (i.e. the tenth order multipole calculation). The superiority of the explicit second-order multipole formulas over the existing zeroth-order and first-order formulas is also demonstrated.

\section{THERMAL $\triangle$ NETWORK FOR SINGLE U-TUBE}

The concept of thermal resistances in a borehole is best discussed with the help of a thermal resistance network. Several representations of the thermal resistance network are possible (Hellström, 1991; Liao et al., 2012; Spitler et al., 2016b), but any such representation is an approximation to reality under network-specific assumptions and restrictions. The simplest approach is to consider a $\Delta$ thermal network as shown in Figure 1.
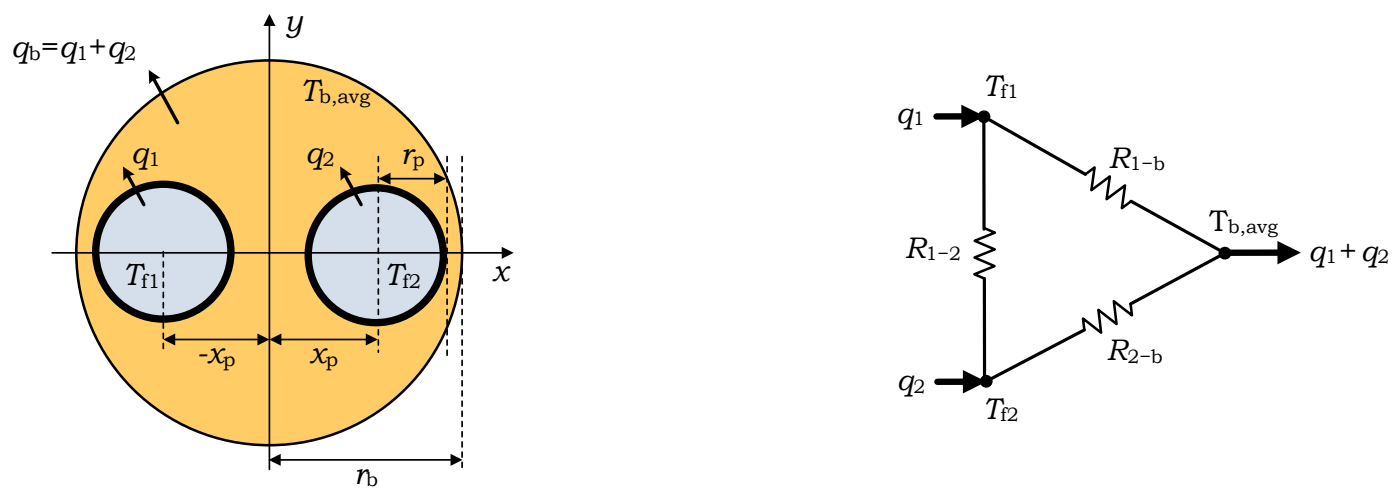

Figure 1 Notations and definitions (left), and $\Delta$ resistance network (right) for a borehole with a single U-tube. 
The above network is based on heat flows $q_{1}$ and $q_{2}$, fluid temperatures $T_{\mathrm{f} 1}$ and $T_{\mathrm{f} 2}$, and thermal resistances $R_{1-\mathrm{b}}, R_{2-\mathrm{b}}$ and $R_{1-2}$ as defined by Equation 5 . The resistance $R_{1-b}$ is between pipe 1 and borehole wall, resistance $R_{2-b}$ is between pipe 2 and borehole wall, and resistance $R_{1-2}$ is between pipe 1 and pipe 2 . The thermal resistance network and Equation

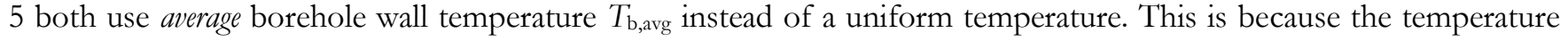
distribution on the borehole wall is non-uniform. This is further discussed in Claesson and Hellström (2011).

$$
q_{1}=\frac{T_{\mathrm{f} 1}-T_{\mathrm{b}, \mathrm{avg}}}{R_{1-\mathrm{b}}}+\frac{T_{\mathrm{f} 1}-T_{\mathrm{f} 2}}{R_{1-2}}, \quad q_{2}=\frac{T_{\mathrm{f} 2}-T_{\mathrm{b}, \mathrm{avg}}}{R_{2-\mathrm{b}}}+\frac{T_{\mathrm{f} 2}-T_{\mathrm{f} 1}}{R_{1-2}}
$$

In an actual installation, pipes 1 and 2 may be located anywhere in the borehole as long as they do not overlap each other. In reality, the position of pipes also varies along the depth of the borehole. In the absence of any a priori knowledge of the pipes position, it is customary to assume that two pipes are symmetrically placed about the center of the borehole. For two equal diameter pipes, this assumption leads to the conclusion that $R_{1-b}=R_{2-b}$. The problem can be further simplified by prescribing the heat fluxes $q_{1}$ and $q_{2}$ as even (i.e. $q_{1}=q_{2}$ ) and odd (i.e. $q_{1}=-q_{2}$ ).

Even Case

Odd Case

$$
\begin{aligned}
& q_{1}=q_{2} \quad \Rightarrow \quad T_{\mathrm{f} 1}^{+}-T_{\mathrm{b}, \mathrm{avg}}=R_{J}^{+} \cdot q_{1} \\
& q_{1}=-q_{2} \Rightarrow T_{\mathrm{f} 1}^{-}-T_{\mathrm{b}, \mathrm{avg}}=R_{J}^{-} \cdot q_{1}
\end{aligned}
$$

Here $T_{\mathrm{f} 1}^{+}$and $T_{\mathrm{f} 1}^{-}$are fluid temperaturtes, and $R_{J}^{+}$and $R_{J}^{-}$are thermal resistances for even and odd cases as defined by Equations 6 and 7, respectively. The corresponding thermal networks for even and odd cases are shown in Figure 2. The subscript $J$ in Equations 6 and 7 refers to the number of multipoles considered at each pipe for the calculation. For $J=0$, only line sources at the pipes are used. The accuracy increases with the number of multipoles used. Closed-form zeroth-order (i.e. $J=0$ ) and first-order (i.e. $J=1$ ) multipole formulas for calculating the borehole thermal resistance and the total internal thermal resistance are already available for the case of two symmetrical pipes (Hellström, 1991). In this paper newly-derived explicit second-order multipole formulas for calculating the borehole thermal resistance and the total internal thermal resistance resistances are presented.

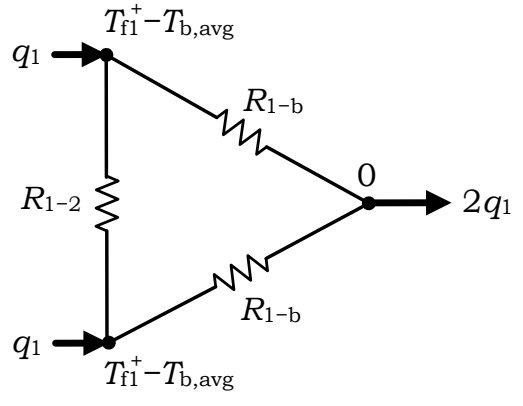

(a)

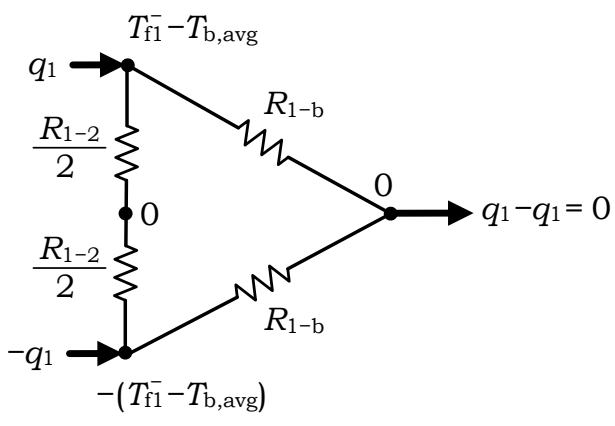

(b)

Figure $2 \quad \Delta$ resistance networks for (a) even and (b) odd cases.

The general expressions for borehole thermal resistance and total internal thermal resistance can be derived from the thermal networks of even and the odd cases, respectively. As can be inferred from Figure 2a, the borehole thermal resistance $R_{b}$ between the fluid in the pipes and the borehole wall consists of two equal resistances (each of value $R_{1-b}$ ) in parallel. On the other hand, as can be deduced from Figure $2 b$, the total internal thermal resistance $R_{a}$ between the two pipes consists of a pair of equal series resistances (each of value $0.5 R_{1-2}$ ) connected in parallel to another pair of equal series resistances (each of value $R_{1-b}$ ). 


$$
R_{\mathrm{b}}=\frac{R_{1-\mathrm{b}}}{2}, \quad R_{\mathrm{a}}=\frac{2 R_{1-\mathrm{b}} R_{1-2}}{2 R_{1-\mathrm{b}}+R_{1-2}}
$$

The relationship between network resistances $R_{1-\mathrm{b}}$ and $R_{1-2}$, and even and odd thermal resistances $R_{J}^{+}$and $R_{J}^{-}$can be obtained from Figure 2 and Equations. 6 and 7.

$$
R_{J}^{+}=R_{1-\mathrm{b}}, \quad \frac{1}{R_{J}^{-}}=\frac{1}{R_{1-\mathrm{b}}}+\frac{2}{R_{1-2}}
$$

For second-order multipole (i.e. $J=2$ ), Equations 8 and 9 can be rearranged to give:

$$
R_{1-\mathrm{b}}=R_{2}^{+}, \quad R_{1-2}=\frac{2 R_{2}^{+} R_{2}^{-}}{R_{2}^{+}-R_{2}^{-}}
$$

The borehole thermal resistance $R_{b}$ and the total internal thermal resistance $R_{a}$ from Equation 8 can now be expressed in terms of thermal resistances $R_{2}^{+}$and $R_{2}^{-}$using Equation 10.

$$
R_{\mathrm{b}}=\frac{R_{2}^{+}}{2}, \quad R_{\mathrm{a}}=2 R_{2}^{-}
$$

The explicit formulas for $R_{2}^{+}$and $R_{2}^{-}$are given by Equations 12 and 13. The derivation of these expressions will not be presented here due to space limitations. The full derivation and mathematical details appear in a technical report by Claesson (2016).

$$
\begin{gathered}
R_{2}^{+}=\frac{1}{2 \pi \lambda_{\mathrm{b}}}\left[\beta+\ln \left(\frac{r_{\mathrm{b}}^{2}}{2 r_{\mathrm{p}} x_{\mathrm{p}}}\right)+\sigma \cdot \ln \left(\frac{r_{\mathrm{b}}^{4}}{r_{\mathrm{b}}^{4}-x_{\mathrm{p}}^{4}}\right)\right]-B_{2}^{+} \\
R_{2}^{-}=\frac{1}{2 \pi \lambda_{\mathrm{b}}}\left[\beta+\ln \left(\frac{2 x_{\mathrm{p}}}{r_{\mathrm{p}}}\right)+\sigma \cdot \ln \left(\frac{r_{\mathrm{b}}^{2}+x_{\mathrm{p}}^{2}}{r_{\mathrm{b}}^{2}-x_{\mathrm{p}}^{2}}\right)\right]-B_{2}^{-} \\
\beta=2 \pi \lambda_{\mathrm{b}} R_{\mathrm{p}}, \quad \sigma=\frac{\lambda_{\mathrm{b}}-\lambda}{\lambda_{\mathrm{b}}+\lambda}
\end{gathered}
$$

The $B_{2}^{ \pm}$values are obtained from the following set of equations. In all following equations, the upper index ' + ' corresponds to the even case and $s=+1$, and the upper index '-' corresponds to the odd case and $s=-1$.

$$
\begin{aligned}
& B_{2}^{ \pm}=\frac{1}{2 \pi \lambda_{\mathrm{b}}} \cdot \frac{b_{1}\left(V_{1}^{ \pm}\right)^{2}\left(2+b_{2} A_{2,2}^{ \pm}\right)-2 b_{1} b_{2} V_{1}^{ \pm} V_{2}^{ \pm} A_{1,2}^{ \pm}+b_{2}\left(V_{2}^{ \pm}\right)^{2}\left(1+b_{1} A_{1,1}^{ \pm}\right)}{\left(1+b_{1} A_{1,1}^{ \pm}\right)\left(2+b_{2} A_{2,2}^{ \pm}\right)-b_{1} b_{2}\left(A_{1,2}^{ \pm}\right)^{2}} \\
& V_{1}^{ \pm}=-s \cdot p_{0}+\sigma p_{1}-s \cdot \sigma p_{2}, \quad V_{2}^{ \pm}=s \cdot p_{0}^{2}+\sigma p_{1}^{2}+s \cdot \sigma p_{2}^{2}, \quad s= \pm 1 \\
& b_{1}=\frac{1-\beta}{1+\beta}, \quad b_{2}=\frac{1-2 \beta}{1+2 \beta}, \quad p_{0}=\frac{r_{\mathrm{p}}}{2 x_{\mathrm{p}}}, \quad p_{1}=\frac{r_{\mathrm{p}} x_{\mathrm{p}}}{r_{\mathrm{b}}^{2}-x_{\mathrm{p}}^{2}}, \quad p_{2}=\frac{r_{\mathrm{p}} x_{\mathrm{p}}}{r_{\mathrm{b}}^{2}+x_{\mathrm{p}}^{2}} \\
& A_{1,1}^{ \pm}=p_{0}^{2} \cdot s+\sigma\left[p_{1}\left(p_{1}+2 p_{0}\right)+p_{2}\left(p_{2}-2 p_{0}\right) \cdot s\right], \quad s= \pm 1 \\
& A_{1,2}^{ \pm}=-2 p_{0}^{3} \cdot s+2 \sigma\left[p_{1}^{2}\left(p_{1}+2 p_{0}\right)-p_{2}^{2}\left(p_{2}-2 p_{0}\right) \cdot s\right] \\
& A_{2,2}^{ \pm}=6 p_{0}^{4} \cdot s+2 \sigma\left[p_{1}^{2}\left(3 p_{1}^{2}+8 p_{0} p_{1}+4 p_{0}^{2}\right)+p_{2}^{2}\left(3 p_{2}^{2}-8 p_{0} p_{2}+4 p_{0}^{2}\right) \cdot s\right]
\end{aligned}
$$




\section{COMPARISON WITH EXISTING MULTIPOLE SOLUTIONS}

In this section the second-order multipole formulas for borehole thermal resistance and total internal thermal resistance are compared with previously published results. The comparison is made using a reference dataset provided by Javed and Spitler (2017). The authors have compared and benchmarked the borehole thermal resistance estimations from 10 different analytical methods against the tenth-order multipole method for 216 different cases. The authors have showed that compared to other methods, the results of zeroth-order and first-order multipole formulas provide greater accuracies. In this paper, we will also benchmark the new second-order multipole formulas against the tenth-order multipole method. The second-order multipole formulas will also be compared to the zeroth-order and first-order multipole formulas to demonstrate improvements in the accuracy of the calculated results.

Table 1 provides the detailed summary of the 216 comparison cases provided by the reference dataset and used in this paper for the comparison of the second-order multipole formulas. The cases cover three different borehole diameters of $96 \mathrm{~mm}, 192 \mathrm{~mm}$, and $288 \mathrm{~mm}$. The U-tube outer pipe diameter value is held fixed at $32 \mathrm{~mm}$ for all cases. The total pipe resistance $R_{\mathrm{p}}$ also remains constant at $0.05 \mathrm{~m}-\mathrm{K} / \mathrm{W}$. For each borehole diameter, three shank spacing configurations, i.e. close, moderate and wide - corresponding, respectively, to Paul's (1996) Configuration A, Configuration B and Configuration $\mathrm{C}$ - are considered. Four levels of ground thermal conductivity ranging from 1-4 $\mathrm{W} / \mathrm{m}-\mathrm{K}$, and six levels of grout thermal conductivity ranging from $0.6-3.6 \mathrm{~W} / \mathrm{m}-\mathrm{K}$ are used. Given the existing and reasonably foreseeable values of design parameters, the 216 cases used for the comparison bracket almost all real-world single U-tube borehole heat exchangers.

Table 1. Summary of Comparison Cases Provided by Javed and Spitler (2017).

Parameter Levels

Ratio of the borehole radius to outer pipe diameter $\left(2 r_{b} / 2 r_{p}\right)$.

Since pipe outer diameter $\left(2 r_{p}\right)$ is always fixed at $32 \mathrm{~mm}$,

borehole diameters $\left(2 r_{b}\right)$ are $96 \mathrm{~mm}, 192 \mathrm{~mm}$, and $288 \mathrm{~mm}$.
$3,6,9$

3

\begin{tabular}{lcc}
\hline & Close, Moderate, Wide \\
Shank spacing configuration; corresponds to Paul's (1996) & $\begin{array}{c}\text { For } r_{b} / r_{p}=3,2 x_{\mathrm{p}}=32 \mathrm{~mm}, 43 \mathrm{~mm}, 64 \mathrm{~mm} \\
\text { A, B, C configurations }\end{array}$ & $\begin{array}{c}\text { For } r_{b} / r_{p}=6,2 x_{\mathrm{p}}=32 \mathrm{~mm}, 75 \mathrm{~mm}, 160 \mathrm{~mm} \\
\text { For } r_{b} / r_{p}=9,2 x_{\mathrm{p}}=32 \mathrm{~mm}, 107 \mathrm{~mm}, 256 \mathrm{~mm}\end{array}$ \\
\hline$\lambda$ - the ground thermal conductivity $(\mathrm{W} / \mathrm{m}-\mathrm{K})$ & $1,2,3,4$ & 4 \\
\hline$\lambda_{g}$ - the grout thermal conductivity $(\mathrm{W} / \mathrm{m}-\mathrm{K})$ & $0.6,1.2,1.8,2.4,3.0,3.6$ & 6 \\
\hline
\end{tabular}

Figures 3-5 present a selection of the comparison results to demonstrate the efficacy of the second-order multipole formulas presented in this paper. The results shown in these figures are for a single ground thermal conductivity of 4.0 $\mathrm{W} / \mathrm{m}-\mathrm{K}$. The left-side figures show the grout thermal resistance values, and the right-side ones show the total internal thermal resistance values, plotted against the grout thermal conductivity. Each figure presents three curves corresponding to close, moderate and wide shank spacing. The exact value of the shank spacing for each case is provided in Table 1. It must be pointed out that multipole formulas presented in the previous section, calculate the borehole thermal resistance and not the grout thermal resistance. However, in order to be consistent with the dataset provided by Javed and Spitler (2017), the values of grout thermal resistance have been calculated and presented in Figures 3-5. The grout thermal resistance values have been determined by subtracting the fixed pipe resistance of $0.05 \mathrm{~m}-\mathrm{K} / \mathrm{W}$ from the corresponding borehole thermal resistance values obtained from the multipole formulas. Computing the grout thermal resistance directly by disregarding the pipe resistance (i.e. setting $\beta=0$ ) in Equations 12 and 13 gives erroneous results for all but zeroth-order multipole calculations. 

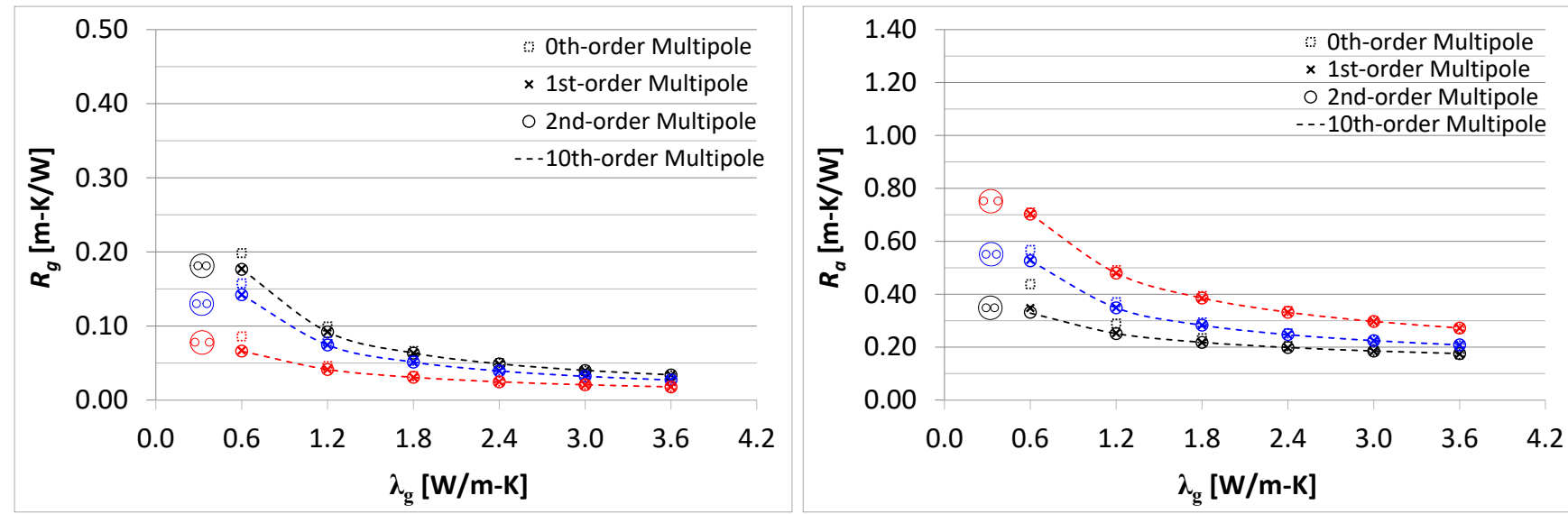

Figure 3 Grout thermal resistance $\left(R_{\mathrm{g}}\right)$ and total internal resistance $\left(R_{\mathrm{a}}\right)$ for close $\left(2 x_{\mathrm{p}}=32 \mathrm{~mm}\right)$, moderate $\left(2 x_{\mathrm{p}}=43 \mathrm{~mm}\right)$ and wide $\left(2 x_{\mathrm{p}}=64 \mathrm{~mm}\right)$ configurations with $2 r_{\mathrm{b}}=96 \mathrm{~mm}$ and $\lambda=4 \mathrm{~W} / \mathrm{m}-\mathrm{K}$.
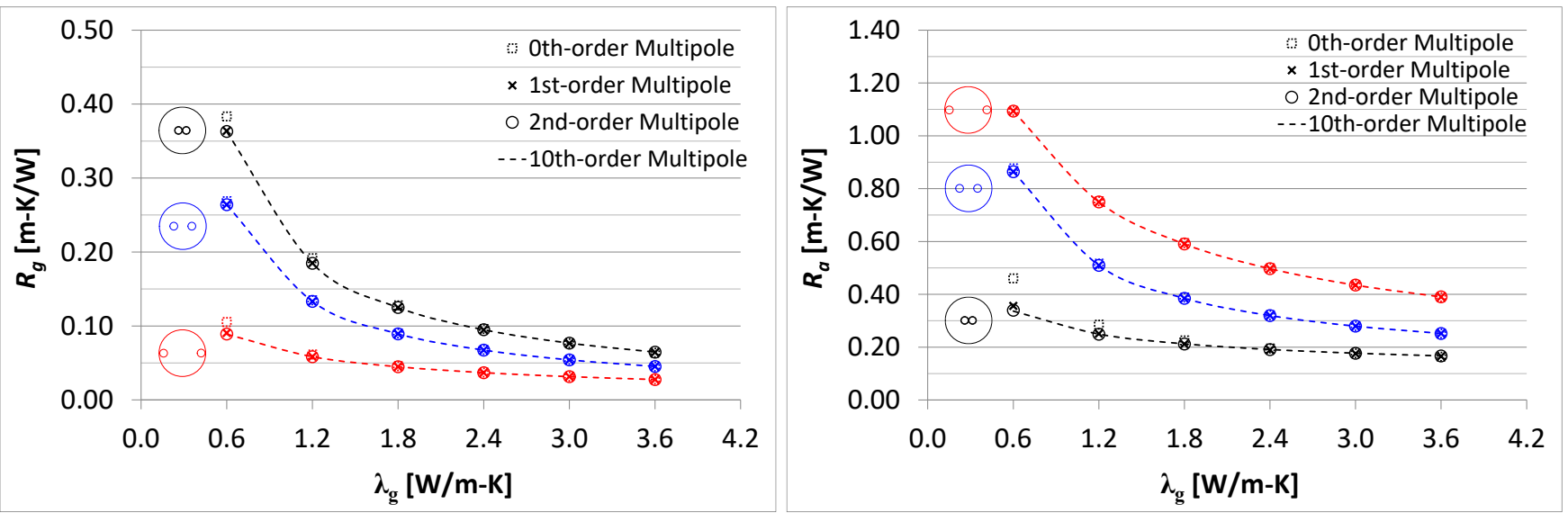

Figure 4 Grout thermal resistance $\left(R_{\mathrm{g}}\right)$ and total internal resistance $\left(R_{\mathrm{a}}\right)$ for close $\left(2 x_{\mathrm{p}}=32 \mathrm{~mm}\right)$, moderate $\left(2 x_{\mathrm{p}}=75 \mathrm{~mm}\right)$ and wide $\left(2 x_{\mathrm{p}}=160 \mathrm{~mm}\right)$ configurations with $2 r_{\mathrm{b}}=192 \mathrm{~mm}$ and $\lambda=4 \mathrm{~W} / \mathrm{m}-\mathrm{K}$.
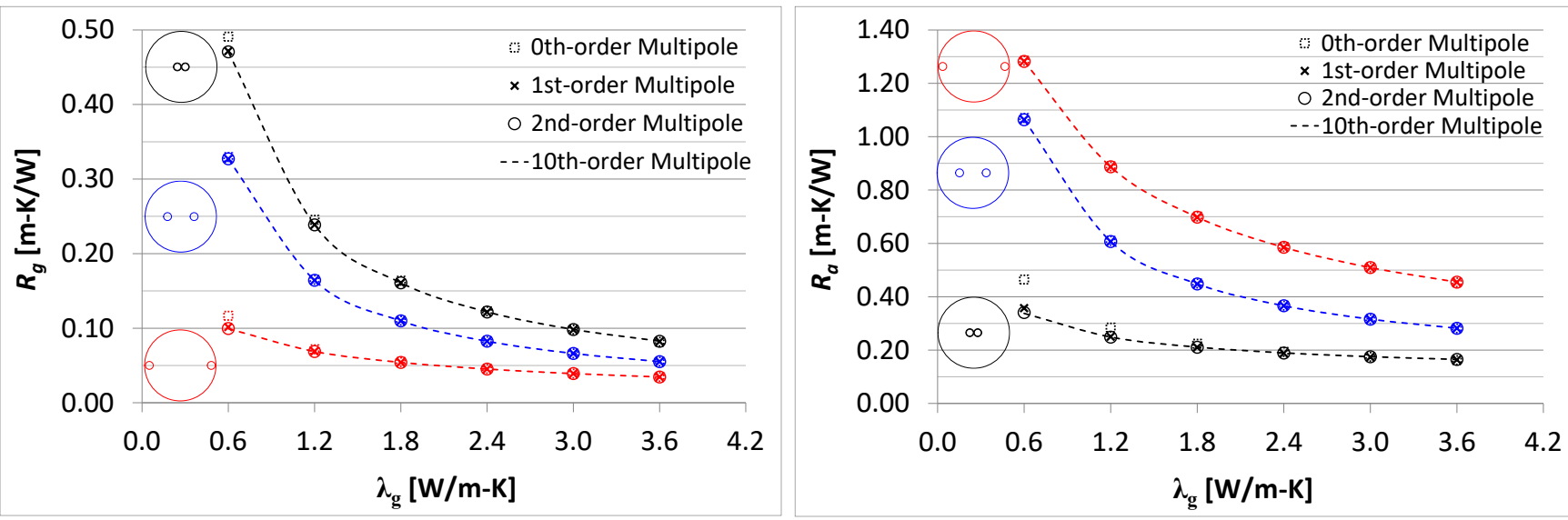

Figure 5 Grout thermal resistance $\left(R_{g}\right)$ and total internal resistance $\left(R_{a}\right)$ for close $\left(2 x_{p}=32\right.$ mm $)$, moderate $\left(2 x_{p}=\right.$ $107 \mathrm{~mm})$ and wide $\left(2 x_{\mathrm{p}}=256 \mathrm{~mm}\right)$ configurations with $2 \mathrm{r}_{\mathrm{b}}=288 \mathrm{~mm}$ and $\lambda=4 \mathrm{~W} / \mathrm{m}-\mathrm{K}$. 
Table 2. Mean and Maximum Absolute Percentage Errors in Calculation of the Grout Thermal Resistance for All 216 Cases.

\begin{tabular}{|c|c|c|c|c|c|c|c|}
\hline \multirow{3}{*}{ Method } & \multirow{3}{*}{$\begin{array}{l}\text { Shank Spacing } \\
\text { Configuration }\end{array}$} & \multicolumn{6}{|c|}{ Grout Conductivity } \\
\hline & & \multicolumn{2}{|c|}{$\begin{array}{c}\text { Low } \\
(0.6-1.2 \mathrm{~W} / \mathrm{m}-\mathrm{K})\end{array}$} & \multicolumn{2}{|c|}{$\begin{array}{c}\text { Moderate } \\
(1.2-2.4 \mathrm{~W} / \mathrm{m}-\mathrm{K})\end{array}$} & \multicolumn{2}{|c|}{$\begin{array}{c}\text { High } \\
(2.4-3.6 \mathrm{~W} / \mathrm{m}-\mathrm{K})\end{array}$} \\
\hline & & Mean & Max & Mean & Max & Mean & Max \\
\hline \multirow{3}{*}{ Zeroth-order Multipole } & Close & 6.1 & 12.4 & 2.9 & 8.0 & 1.0 & 2.5 \\
\hline & Moderate & 3.3 & 10.8 & 1.5 & 6.5 & 0.4 & 1.6 \\
\hline & Wide & 8.9 & 30.4 & 1.9 & 11.2 & 0.3 & 1.8 \\
\hline \multirow{3}{*}{ First-order Multipole } & Close & 0.2 & 0.4 & 0.2 & 0.6 & 0.7 & 1.5 \\
\hline & Moderate & 0.0 & 0.2 & 0.0 & 0.2 & 0.1 & 0.5 \\
\hline & Wide & 0.5 & 2.2 & 0.0 & 0.2 & 0.1 & 0.6 \\
\hline \multirow{3}{*}{ Second-order Multipole } & Close & 0.0 & 0.0 & 0.1 & 0.2 & 0.2 & 0.5 \\
\hline & Moderate & 0.0 & 0.0 & 0.0 & 0.1 & 0.0 & 0.1 \\
\hline & Wide & 0.1 & 0.3 & 0.0 & 0.0 & 0.0 & 0.1 \\
\hline
\end{tabular}

Results of the second-order multipole formulas for calculating the borehole thermal resistance and the total internal thermal resistance are summarized in Tables 2 and 3, respectively. It should be noted that although Figures 3-5 only showed results for ground thermal conductivity value of $4 \mathrm{~W} / \mathrm{m}-\mathrm{K}$ due to space limitations, the results presented in Tables 2 and 3 have been obtained considering all ground thermal conductivity values from $1-4 \mathrm{~W} / \mathrm{m}-\mathrm{K}$. Each entry in these two tables represents the mean or maximum error in percentage for a sample containing two-three values of grout thermal conductivity, three values of borehole diameter, and four values of ground thermal conductivity. The errors have been determined by comparing the results of second-order multipole formulas to the tenth-order multipole method. For the ease of comparison, errors from zeroth-order and first-order multipole formulas, as reported by Javed and Spitler (2017), are included as well.

Table 2 shows that the grout thermal resistance values obtained from the second-order multipole formula are within $0.5 \%$ of the tenth-order multipole method for all 216 cases. Also, the mean absolute percentage error of the results obtained from the second-order multipole formula is smaller than $0.2 \%$. In comparison, the mean and maximum absolute percentage errors for the zeroth-order multipole formula are as high as $9 \%$ and $30 \%$, respectively. The firstorder multipole formula has smaller errors than the zeroth-order formula. Nevertheless, compared to the second-order multipole formula, the errors from the first-order multipole formula are higher by several orders of magnitude.

Table 3. Mean and Maximum Absolute Percentage Errors in Calculation of the Total Internal Thermal Resistance for All 216 Cases.

\begin{tabular}{|c|c|c|c|c|c|c|c|}
\hline \multirow{3}{*}{ Method } & \multirow{3}{*}{$\begin{array}{l}\text { Shank Spacing } \\
\text { Configuration }\end{array}$} & \multicolumn{6}{|c|}{ Grout Conductivity } \\
\hline & & \multicolumn{2}{|c|}{$\begin{array}{c}\text { Low } \\
(0.6-1.2 \mathrm{~W} / \mathrm{m}-\mathrm{K})\end{array}$} & \multicolumn{2}{|c|}{$\begin{array}{c}\text { Moderate } \\
(1.2-2.4 \mathrm{~W} / \mathrm{m}-\mathrm{K})\end{array}$} & \multicolumn{2}{|c|}{$\begin{array}{c}\text { High } \\
(2.4-3.6 \mathrm{~W} / \mathrm{m}-\mathrm{K})\end{array}$} \\
\hline & & Mean & Max & Mean & Max & Mean & Max \\
\hline \multirow{3}{*}{ Zeroth-order Multipole } & Close & 23.3 & 37.6 & 6.9 & 15.0 & 1.2 & 2.7 \\
\hline & Moderate & 1.8 & 7.8 & 1.1 & 6.0 & 0.3 & 1.8 \\
\hline & Wide & 1.9 & 8.5 & 0.4 & 2.3 & 0.2 & 1.3 \\
\hline \multirow{3}{*}{ First-order Multipole } & Close & 3.2 & 5.9 & 0.6 & 0.7 & 0.7 & 0.7 \\
\hline & Moderate & 0.2 & 0.8 & 0.0 & 0.2 & 0.1 & 0.2 \\
\hline & Wide & 0.3 & 1.2 & 0.0 & 0.1 & 0.0 & 0.1 \\
\hline \multirow{3}{*}{ Second-order Multipole } & Close & 0.4 & 1.0 & 0.2 & 0.2 & 0.1 & 0.2 \\
\hline & Moderate & 0.0 & 0.0 & 0.0 & 0.0 & 0.0 & 0.0 \\
\hline & Wide & 0.0 & 0.2 & 0.0 & 0.0 & 0.0 & 0.0 \\
\hline
\end{tabular}


Table 3 shows that the total internal thermal resistance values calculated from the second order multipole formulas are within $1 \%$ of the tenth-order multipole method for all 216 cases. The mean absolute percentage error of the results obtained from the second-order multipole formula never exceed $0.4 \%$. In comparison, the zeroth-order and the firstorder multipole formulas give maximum absolute percentage errors of approximately $38 \%$ and $6 \%$, respectively. The mean absolute percentage errors of the zeroth-order and the first-order multipole expressions are as high as $23 \%$ and $3 \%$, respectively.

Even though the second-order multipole formulas presented in this paper are more complicated than many other analytical expressions including the zeroth-order and first-order formulas, it is still simple enough to apply for computation purposes. The implementation of the second-order multipole formulas requires approximately 10 lines of coding of rather compact and simple algebraic expressions. This is a significant improvement over the original implementation of the Multipole method, which required about 600 lines of FORTRAN coding. Hence, due to their excellent accuracy and relative ease of implementation, the second-order multipole formulas are recommended for calculation of borehole thermal resistance and total internal thermal resistance for all cases where the two legs of the Utube are placed symmetrically in the borehole.

\section{CONCLUSION}

Closed-form second-order multipole formulas for the calculation of borehole thermal resistance and total internal thermal resistance have been presented in this paper. The presented formulas can be used for all single U-tube applications where the two legs of the U-tube are symmetrically placed in the borehole. The newly-derived formulas have been compared with the original multipole method, as well as the previously-derived zeroth-order and first-order explicit multipole formulas. The second-order multipole formulas provide significant accuracy improvements over the zeroth-order and the first-order multipole formulations. The thermal resistance values calculated from the second-order multipole formulas are always within $1 \%$ of the original tenth-order multipole method. The presented formulas may also be used to estimate the effective borehole thermal resistance from the expressions defined by Equations 3 and 4 .

\section{NOMENCLATURE}

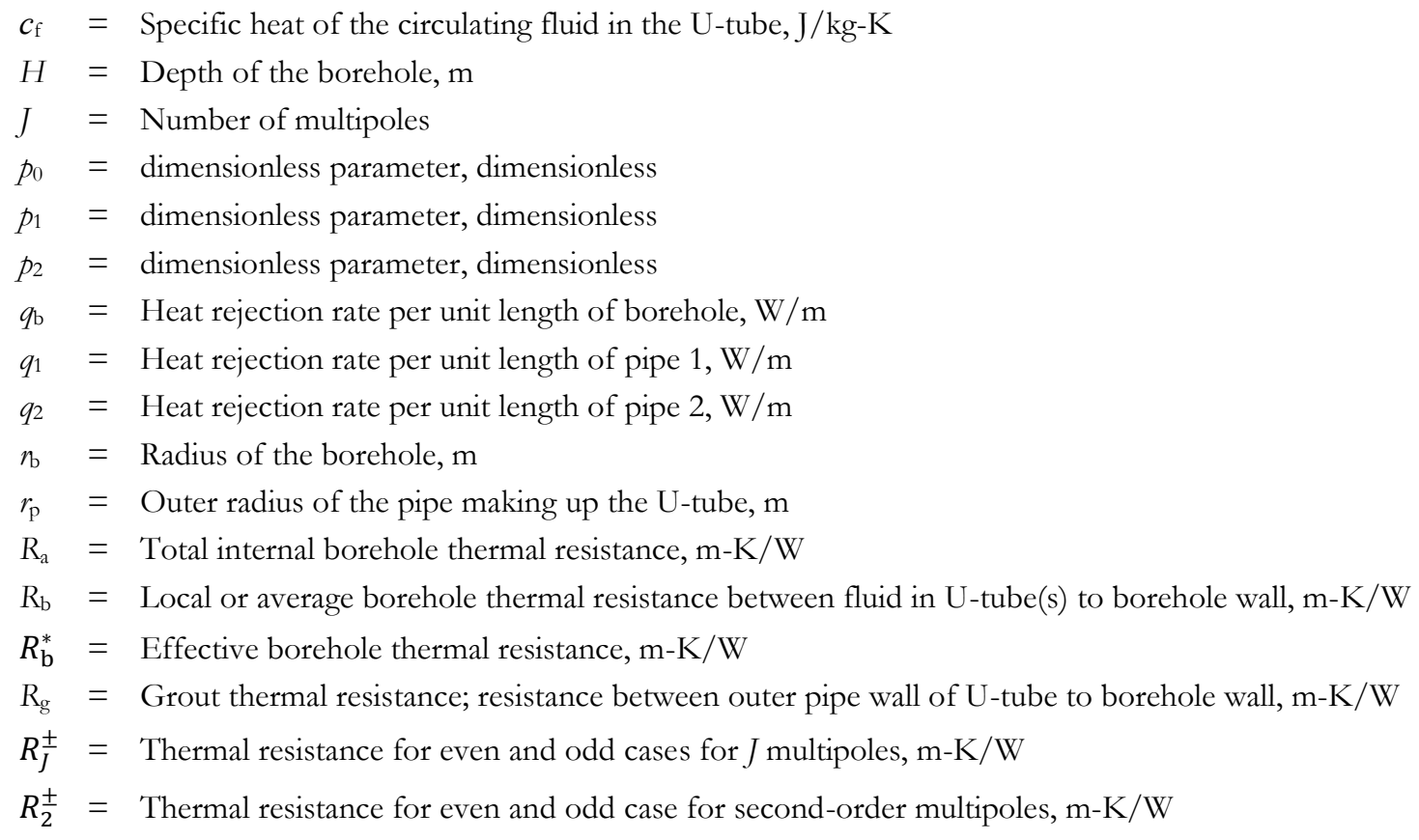




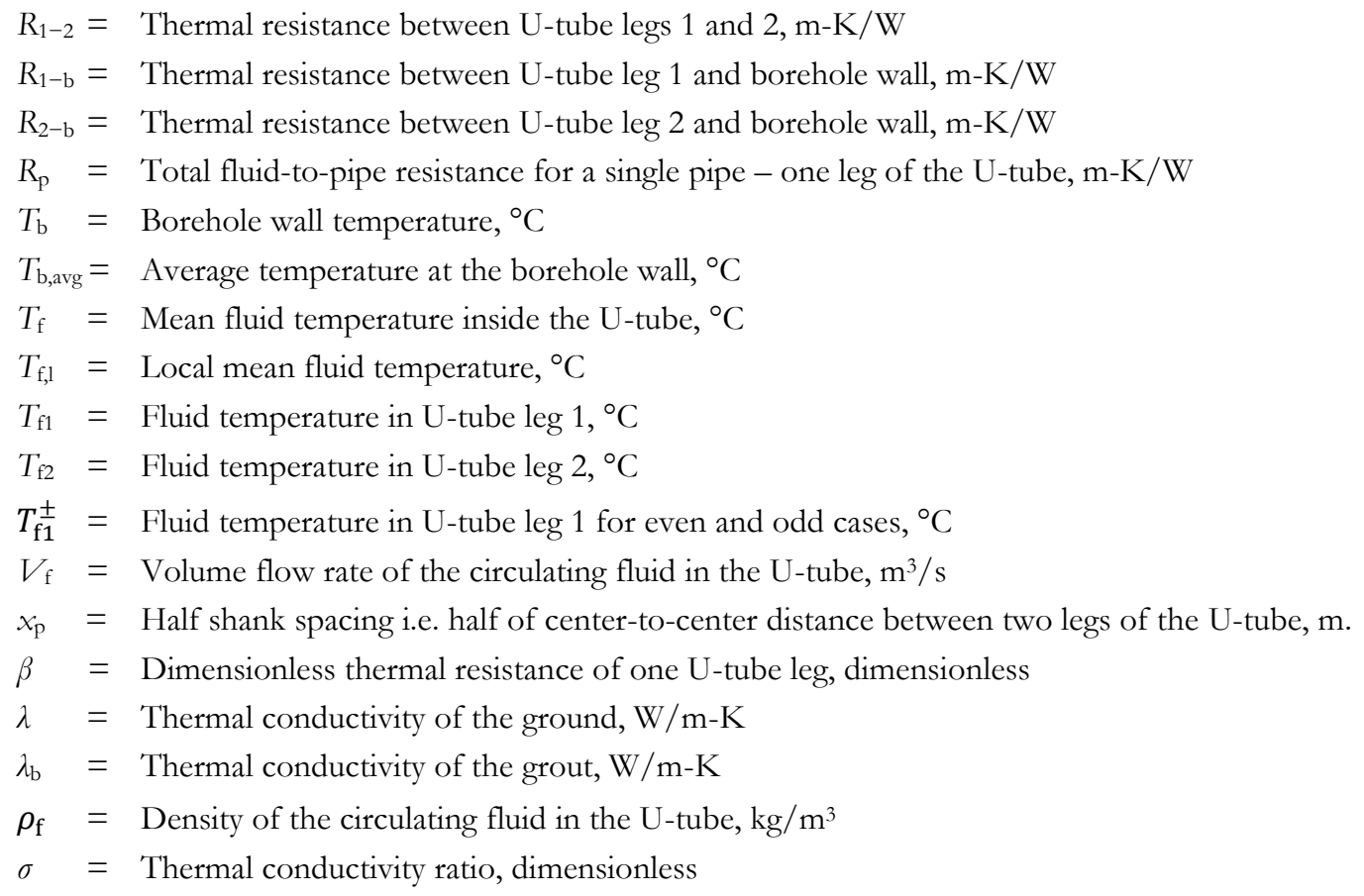

\section{REFERENCES}

Bennet, J., J. Claesson and G. Hellström. 1987. Multipole method to compute the conductive beat flows to and between pipes in a composite cylinder. Notes on Heat Transfer 3, University of Lund, Sweden.

BLOCON. 2015. EED v3.2.

Claesson, J. 2012. Multipole method to calculate borehole thermal resistances. Mathematical Report, Chalmers University of Technology, Sweden.

Claesson, J. 2016. Multipole method to calculate borehole thermal resistances. Mathematical Report 2 - Additions to background report from June 2012. Mathematical Report, Chalmers University of Technology, Sweden.

Claesson, J. and G. Hellström. 2011. Multipole method to calculate borehole thermal resistances in a borehole heat exchanger. HVAC\&R Research 17(6): 895-911.

Hellström, G. 1991. Ground Heat Storage - Thermal Analyses of Duct Storage Systems - Theory. PhD Doctoral Thesis, University of Lund, Sweden.

Javed, S., H. Nakos, and J. Claesson. 2012. A method to evaluate thermal response tests on groundwater-filled boreholes. ASHRAE Transactions 118(1): 540-549.

Javed, S. and J.D. Spitler. 2016. Calculation of borehole thermal resistance. In Advances in Ground-Source Heat Pump Systems, edited by Simon J. Rees. Woodhead Publishing, Pages 63-95. http://dx.doi.org/10.1016/B978-0-911 08-100311-4.00003-0.

Javed, S. and J.D. Spitler. 2017. Accuracy of borehole thermal resistance calculation methods for grouted single U-tube ground heat exchangers. Applied Energy, Accepted for Publication.

Liao, Q., C. Zhou, W. Cui and T. C. Jen. 2012. New Correlations for Thermal Resistances of Vertical Single U-Tube Ground Heat Exchanger. Journal of Thermal Science and Engineering Applications 4(3): 031010.

Lund, J. W. and T. L. Boyd. 2016. Direct utilization of geothermal energy 2015 worldwide review. Geothermics 60 (2016): 66-93.

Ma, W., M. Li, P. Li, and A.C. Lai. 2015. New quasi-3D model for heat transfer in U-shaped GHEs (ground heat exchangers): Effective overall thermal resistance. Energy 90: 578-587.

Paul, N. D. 1996. The effect of grout thermal conductivity on vertical geothermal heat exchanger design and performance. Master's Thesis, South Dakota University, USA.

Spitler, J. D. 2000. GLHEPRO - A Design Tool for Commercial Building Ground Loop Heat Exchangers. Fourth International Heat Pumps in Cold Climates Conference, Aylmer, Québec. 
Spitler, J D., R. Grundmann and S. Javed. 2016a. Calculation Tool for Effective Borehole Thermal Resistance. In Proceedings of the 12th REHVA World Congress (Clima 2016), Aalborg, Denmark, May 22 - 25, 2016.

Spitler, J. D., S. Javed and R. K. Ramstad. 2016b. Natural convection in groundwater-filled boreholes used as ground beat exchangers. Applied Energy 164: 352-365.

Zeng, H., N. Diao, and Z. Fang. 2003. Heat transfer analysis of boreholes in vertical ground heat exchangers. International Journal of Heat and Mass Transfer 46(23): 4467-4481. 